\title{
TESTE DE TETRAZÓLIO EM SEMENTES DE Copaifera langsdorffii E Schizolobium parahyba
}

\author{
Cristiane Alves Fogaça ${ }^{1}$; Nádia Graciele Krohn² ${ }^{2}$ Márcio de Aquino Souza ${ }^{3}$; Rinaldo César de Paula ${ }^{4}$ \\ ${ }^{1}$ Eng ${ }^{\mathrm{a}}$ Agrônoma, Dr ${ }^{\mathrm{a}}$., Depto. de Agronomia, FACIAGRA, Ouricuri, PE, Brasil - fogacac@yahoo.com.br \\ ${ }^{2}$ Eng $^{\mathrm{a}}$ Agrônoma, M.Sc., Depto. de Biologia Celular e Fisiologia de Plantas, Universidade de Regensburgo, Regensburgo, Alemanha \\ - nadiakrohn@yahoo.com.br \\ ${ }^{3}$ Eng. Agrônomo, CVale, Nova Mutum, MT, Brasil - marcioaq@cvale.com.br \\ ${ }^{4}$ Eng. Florestal, Dr., Depto. de Produção Vegetal, UNESP/FCAV, Jaboticabal, SP, Brasil - rcpaula@ fcav.unesp.br
}

Recebido para publicação: 02/11/2009 - Aceito para publicação: 01/06/2011

\begin{abstract}
Resumo
Este trabalho objetivou padronizar o teste de tetrazólio para avaliação da viabilidade de sementes de copaíba e guapuruvu. Avaliou as seguintes metodologias: sementes escarificadas mecanicamente e embebidas por 24 e 48 horas, com posterior retirada do tegumento e imersas em solução de tetrazólio a $0,075,0,10$ e $0,20 \%$ por 2,3 e 4 horas, a $35{ }^{\circ} \mathrm{C}$, no escuro. As metodologias avaliadas que foram eficientes na obtenção de coloração satisfatória, permitindo a diferenciação dos tecidos, e na avaliação da qualidade fisiológica das sementes, quando comparadas com o teste padrão de germinação, foram: para a espécie copaíba, sementes escarificadas e embebidas por 24 horas, a $35^{\circ} \mathrm{C}$, com posterior retirada do tegumento, submetidas a solução de tetrazólio a $0,20 \%$ por 4 horas, a $35{ }^{\circ} \mathrm{C}$, no escuro; e para a espécie guapuruvu, sementes escarificadas e embebidas por 48 horas, a $35^{\circ} \mathrm{C}$, com posterior retirada do tegumento, submetidas a solução de tetrazólio a $0,10 \%$ por 4 horas, a $35^{\circ} \mathrm{C}$, no escuro.

Palavras-chave: Sementes florestais; teste rápido; copaíba; guapuruvu.
\end{abstract}

\begin{abstract}
Tetrazolium test in Copaifera langsdorffii and Schizolobium parahyba seeds. This research aimed to standardize the tetrazolium test for evaluation of viability of Copaifera langsdorffii Desf. and Schizolobium parahyba Vell. Blake seeds. It evaluated the following methodologies: seeds scarificated mechanically and soaked up by 24 and 48 hours, with posterior seed coat removal and immersed in tetrazolium solution at $0.075 ; 0.10$ and $0.20 \%$ for 2,3 and 4 hours, $35^{\circ} \mathrm{C}$, the dark one. The evaluated methodologies that had been efficient in the attainment of satisfactory coloration, allowing the differentiation of tissues, and in the evaluation of the physiological quality of the seeds when compared with the germination test, had been: for the species Copaifera langsdorffii, seeds scarificated and soaked up by 24 hours, $35^{\circ} \mathrm{C}$, with posterior seed coat removal, submitted to the tetrazolium solution $0.20 \%$ for 4 hours, $35^{\circ} \mathrm{C}$, in the dark one, and for the species guapuruvu, seeds scarificated and soaked up by 48 hours, $35^{\circ} \mathrm{C}$, with posterior seed coat removal, submitted to the tetrazolium solution $0.10 \%$ for 4 hours, $35^{\circ} \mathrm{C}$, in the dark one.

Keywords: Forest seeds; fast test; Copaifera langsdorffii; Schizolobium parahyba.
\end{abstract}

\section{INTRODUÇÃO}

Copaíba (Copaifera langsdorffii Desf.), também conhecida como óleo-de-copaíba e pau-de-óleo, entre outras denominações, é recomendada para plantios em áreas degradadas de preservação permanente. As sementes dessa espécie sem qualquer tratamento levam de 20 a 40 dias para germinar (LORENZI, 2000).

Guapuruvu (Schizolobium parahyba Vell. Blake) é recomendado para recuperação de áreas degradadas de preservação permanente em composições mistas. As sementes dessa espécie, quando escarificadas, levam de 5 a 15 dias para germinar (LORENZI, 2000). Esse é o período necessário para obtenção dos resultados de viabilidade de um lote de sementes através do teste padrão de germinação.

Por se tratar de um teste confiável e reproduzível, o teste de germinação é o mais utilizado para avaliar a qualidade fisiológica de sementes de várias espécies. Porém esse teste apresenta várias 
limitações: não possibilita a identificação precisa dos fatores que afetam a qualidade, não detecta algumas sutilezas na deterioração das sementes e não prediz o resultado do desempenho das sementes em condições gerais de campo e o potencial de armazenamento (FRANÇA-NETO et al., 1986; DELOUCHE, 1995).

O fator tempo é um dos fatores limitantes para a realização do teste de germinação, principalmente de espécies florestais. O uso de testes mais rápidos, visando dar ao agricultor uma informação precisa e rápida quanto ao desempenho das sementes a campo ou em viveiro, tem sido uma grande vantagem dos produtores mais hábeis (NASCIMENTO; CARVALHO, 1998). Pesquisas objetivando o desenvolvimento de testes rápidos para a avaliação da qualidade fisiológica das sementes têm sido intensificadas, principalmente devido às vantagens proporcionadas pela rapidez dos resultados nos diversos segmentos do processo de produção (AMARAL; PESKE, 1984; FRANCO et al., 1984; FRANÇA-NETO et al., 1986).

Nesse sentido, o teste de tetrazólio vem se destacando nos programas de controle de qualidade de sementes, por ser um método rápido que estima a germinação potencial e o vigor e permite avaliar a possível influência de outros fatores que impedem ou reduzem a emergência de plântulas (COSTA; MARCOS-FILHO, 1994).

De acordo com Piña-Rodrigues e Santos (1988), o teste de tetrazólio mostra-se muito promissor na avaliação da viabilidade em sementes florestais, principalmente para espécies que exigem um longo período de germinação, dificultando a obtenção dos resultados. Para a maioria das espécies, ainda se faz necessário definir procedimentos a serem adotados, sua divulgação e utilização em análise de rotina.

A avaliação da qualidade das sementes através do teste de tetrazólio está baseada na alteração da coloração dos tecidos vivos, em presença de uma solução de sal de tetrazólio, expressando a atividade de enzimas desidrogenases envolvidas na atividade respiratória. Essas enzimas catalizam a reação dos íons $\mathrm{H}^{+}$, que são liberados pela respiração dos tecidos vivos com o sal de tetrazólio (cloreto 2,3,5 trifenil tetrazólio), formando uma substância de coloração vermelha denominada formazam. A reação se processa no interior das células, detectando os tecidos vivos pela formação da coloração vermelha e os tecidos mortos que não respiram ou os muito deteriorados (que liberam pouca quantidade de íons $\mathrm{H}^{+}$, insuficiente para que a reação ocorra), não apresentando coloração (GRABE, 1976; FRANÇA-NETO et al., 1986).

$\mathrm{O}$ teste de tetrazólio permite determinar a viabilidade das sementes de germinação lenta ou que possuem sementes dormentes. Possibilita ainda uma estimativa rápida das condições fisiológicas das sementes quanto à viabilidade e ao vigor, sendo de extrema utilidade para análise de sementes dormentes, e complementa os dados obtidos num teste de germinação, auxiliando no diagnóstico das causas da deterioração das sementes (MORENO, 1984).

Os resultados obtidos com a condução apropriada dos testes de tetrazólio e padrão de germinação, geralmente são bastante concordantes dentro da amplitude normal de variação da amostra. Diferenças de 3-5\% podem ser causadas inteiramente por inevitáveis erros de amostragem. As diferenças em resultados geralmente são menores em sementes de alta qualidade, em espécies de sementes grandes e em lotes uniformes de sementes (GRABE, 1976).

A discrepância entre os resultados dos testes de tetrazólio e de germinação advém das seguintes razões: uma das mais comuns em sementes florestais é que o teste não diferencia sementes dormentes das não dormentes. Assim, nos tipos de sementes com dormência profunda, os resultados do teste de tetrazólio são considerados mais elevados do que os resultados do teste de germinação (GRABE, 1976). Assim, para evitar problemas de discrepâncias entre o teste de tetrazólio e o teste padrão de germinação, recomenda-se que as sementes sejam submetidas a tratamento para superação da dormência antes de realizar o teste padrão de germinação (DELOUCHE et al., 1976; FOGAÇA, 2000).

Baseado nas hipóteses de que o teste de tetrazólio pode ser uma opção eficiente no controle de qualidade de sementes de copaíba e guapuruvu e, ainda, que, quando comparado ao teste de germinação, possa ser empregado como complemento a este, o objetivo deste trabalho foi padronizar o teste de tetrazólio para avaliação da viabilidade de sementes de Copaifera langsdorffii e Schizolobium parahyba.

\section{MATERIAL E MÉTODOS}

O presente trabalho foi conduzido no Laboratório de Tecnologia de Sementes da Faculdade de Ciências Agrárias e Veterinárias (FCAV/UNESP), Jaboticabal, SP, em duas etapas. Na primeira etapa, 
utilizaram-se sementes de Copaifera langsdorffii coletadas em 2000, no campus da FCAV/UNESP, Jaboticabal (SP), e sementes de Schizolobium parahyba provenientes da ARIE (Área de Relevante Interesse Ecológico) situada no município de Santa Helena (PR), testando-se diferentes tratamentos de pré-condicionamento das sementes, concentrações e períodos de exposição das sementes na solução de tetrazólio.

Os tratamentos de pré-condicionamento consistiram em submeter sementes escarificadas manualmente (com lixa $n^{\circ} 80$, na região oposta ao embrião) a 24 e 48 horas de embebição, entre papel de filtro umedecido, e acondicionadas a $35^{\circ} \mathrm{C}$, com posterior retirada do tegumento, evitando-se danos ao embrião.

Após isso, as sementes de cada um dos tratamentos de pré-condicionamento foram submetidas a 2, 3 e 4 horas de embebição em solução de 2,3,5 trifenil cloreto de tetrazólio ( $\mathrm{pH}$ 6,5 a 7,0), nas concentrações de $0,075,0,10$ e $0,20 \%$, em câmara regulada a $35^{\circ} \mathrm{C}$, no escuro.

Conforme a quantidade de sementes de cada lote, utilizaram-se três repetições de 20 sementes de copaíba e quatro repetições de 20 sementes de guapuruvu, para cada tratamento da etapa em questão. As sementes foram expostas à solução de tetrazólio acondicionadas em recipientes plásticos de $200 \mathrm{~mL}$. Vencido o período de exposição das sementes a cada uma das soluções, estas foram drenadas e as sementes lavadas em água corrente, sendo mantidas submersas em água, em ambiente refrigerado, até o momento da avaliação da coloração.

Para avaliação das sementes, uma a uma, elas foram seccionadas longitudinalmente, através do centro do eixo embrionário, com auxílio de um bisturi. Para auxiliar a visualização de todos os detalhes das sementes, foi utilizada uma lupa de mesa com lâmpada fluorescente de seis aumentos (6x).

Os níveis de viabilidade foram caracterizados mediante a representação de oito diagramas de sementes viáveis e inviáveis, observando-se a presença e localização dos danos, além das condições físicas das estruturas embrionárias (Figuras 1 e 2). A diferenciação de cores dos tecidos foi observada de acordo com os critérios estabelecidos para o teste de tetrazólio (DELOUCHE et al., 1976; BHÉRING et al., 1996; FRANÇA-NETO, 1999): vermelho brilhante ou rosa (tecido vivo e vigoroso); vermelhocarmim forte (tecido em deterioração) e branco leitoso ou amarelado (tecido morto).

A definição do melhor pré-tratamento e condições de coloração foi baseada no aspecto dos tecidos e na intensidade e uniformidade de coloração.

A segunda etapa foi realizada com dois lotes de sementes de copaíba coletados no campus da FCAV/UNESP, sendo o Lote 1 coletado em 2000 e o Lote 2 coletado em 2001. Para a espécie guapuruvu, foram utilizados dois lotes coletados no Viveiro Experimental de Plantas Ornamentais e Florestais da FCAV/UNESP, colhidos em 2001 (Lote 1) e 2002 (Lote 2). Os lotes coletados em 2000 e 2001 estavam armazenados em tamboretes de madeira, em câmara fria, até o momento das avaliações.

O objetivo dessa etapa foi avaliar a eficiência do teste de tetrazólio como indicador de viabilidade de sementes das espécies estudadas. Delouche et al. (1976) afirmaram não ser suficiente a comparação entre o teste de tetrazólio e o de germinação apenas uma vez, ou em uma única amostra. Portanto, os lotes utilizados foram divididos em duas amostras, as quais foram submetidas ao teste de germinação e ao teste de tetrazólio, utilizando-se neste o melhor resultado obtido na etapa anterior.

As caracterizações das amostras de cada lote foram realizadas a partir da determinação do grau de umidade, segundo prescrições das Regras para Análise de Sementes/RAS (BRASIL, 1992).

Os testes de germinação foram realizados com três repetições de 20 sementes de copaíba e quatro repetições de 25 sementes de guapuruvu, todas escarificadas manualmente (lixa $\mathrm{n}^{\circ}$ 80, no lado oposto ao embrião). O teste foi conduzido em rolos de papel, em câmara de germinação à temperatura constante de $25{ }^{\circ} \mathrm{C}$ e fotoperíodo de 12 horas. As avaliações foram realizadas diariamente, a partir do momento em que as plântulas apresentaram todas as suas partes desenvolvidas. Os resultados foram expressos em porcentagem de plântulas normais.

Paralelamente aos testes de germinação, foram realizados os testes de tetrazólio, nos quais, para sementes de copaíba, utilizaram-se três repetições de 20 sementes escarificadas para cada amostra dos lotes, submetidas a 24 horas de embebição entre papel de filtro a $35^{\circ} \mathrm{C}$, com posterior retirada do tegumento. As sementes foram imersas em solução de tetrazólio na concentração de $0,20 \%$ por 4 horas, a $35^{\circ} \mathrm{C}$, no escuro. Para a espécie guapuruvu, empregaram-se quatro repetições de 25 sementes previamente escarificadas para cada amostra dos lotes, submetidas a 48 horas de embebição a $35^{\circ} \mathrm{C}$, entre papel de filtro umedecido, com posterior retirada do tegumento. As sementes foram, então, imersas em 
solução de tetrazólio na concentração de $0,10 \%$, por 4 horas, a $35^{\circ} \mathrm{C}$, no escuro. Após esse período, as sementes foram analisadas individualmente, seccionadas longitudinalmente através do centro do eixo embrionário, com auxílio de um bisturi, e observadas com auxílio de uma lupa de mesa com lâmpada fluorescente de seis aumentos $(6 \mathrm{x})$.

Os resultados obtidos nos testes de germinação e tetrazólio de cada amostra dos lotes foram submetidos à análise de variância e as médias comparadas através do teste Tukey, ao nível de 5\% de probabilidade, segundo o delineamento experimental inteiramente casualizado.

\section{RESULTADOS E DISCUSSÃO}

\section{Copaifera langsdorffii - copaíba}

As sementes escarificadas, embebidas por 24 horas e com posterior retirada do tegumento não apresentaram uniformidade de coloração. Muitas sementes não apresentaram coloração na região central do tecido de reserva e no eixo embrionário, colorindo-se apenas nas extremidades das sementes, não permitindo a avaliação. Porém, na concentração de $0,20 \%$ por 4 horas, houve coloração adequada, permitindo a diferenciação dos tecidos sadios, mortos e em processo de deterioração.

As sementes submetidas à escarificação mecânica seguida de embebição por 48 horas, com retirada do tegumento, apresentaram manchas rosadas dispersas no tecido de reserva, sem, contudo, atingir o eixo embrionário. Considerando que o embrião, localizado na parte interna da semente, é a principal estrutura a ser analisada na determinação da viabilidade e vigor, a coloração dela é fundamental. As sementes dessa preparação, quando submetidas a $0,20 \%$ por 4 horas, apresentaram coloração ideal, permitindo a diferenciação e avaliação das condições em que se encontravam os tecidos das sementes. Quando submetidas a concentrações de $0,075,0,10$ e $0,20 \%$ por 2 e 3 horas ou em soluções de 0,075 e $0,10 \%$ por 4 horas, apresentaram muita variação na coloração obtida, não permitindo a diferenciação.

Dos tratamentos avaliados para a adequação do teste de tetrazólio para sementes de Gleditschia amorphoides Taub. (sucará), aquele em que as sementes foram escarificadas e submetidas à embebição por 48 horas com retirada do tegumento apresentou o melhor resultado, obtendo a condição de coloração ideal utilizando concentrações de 0,050 e $0,075 \%$ por 3 e 6 horas e $0,10 \%$ por 1 hora (FOGAÇA et al., 2006).

Na figura 1 está representada em diagrama a classificação dos níveis de viabilidade encontrados no desenvolvimento do teste de tetrazólio para sementes de Copaifera langsdorffii, considerando as seguintes características como ideais: tecidos com coloração vermelha brilhante uniforme ou rósea, típica de tecido sadio, identificação e diferenciação dos tecidos mortos que apresentam coloração branca ou amarelada ou em deterioração com coloração vermelha intensa.

A descrição das classes de viabilidade é a seguinte:

Classe 1 Viável: sementes com coloração rósea uniforme e todos os tecidos com aspecto normal e firme.

Classe 2 Viável: semente com coloração rósea uniforme e região central dos cotilédones e extremidade da radícula apresentando coloração vermelha intensa.

Classe 3 Viável: extremidade da radícula com coloração branca e leitosa e vermelha intensa sem atingir o cilindro central, além de apresentar manchas brancas e leitosas e vermelha intensa dispersas.

Classe 4 Viável: semente apresentando menos de 50\% da região cotiledonar com coloração branca e leitosa, caracterizando tecido morto.

Classe 5 Inviável: eixo embrionário e mais de 50\% da região cotiledonar apresentando coloração vermelha intensa, tecidos em deterioração.

Classe 6 Inviável: semente totalmente com coloração vermelha intensa, indicando processo acentuado de deterioração.

Classe 7 Inviável: pequena região do eixo embrionário e áreas da região cotiledonar com coloração rósea e as demais regiões com coloração branca e leitosa.

Classe 8 Inviável: semente totalmente branca e leitosa, apresentando tecidos flácidos.

Primeiramente, para a avaliação da eficiência do teste de tetrazólio na determinação da viabilidade de sementes de copaíba, caracterizaram-se os lotes a partir do grau de umidade dos lotes 1 e 2 , que foram 9,6 e $9,4 \%$, respectivamente. 
Dentro de cada lote avaliado, as amostras não apresentaram diferença significativa entre os testes de germinação e tetrazólio, o que demonstra que a metodologia do teste de tetrazólio empregada estimou com eficiência a viabilidade das sementes analisadas (Tabela 1).
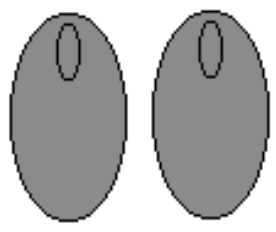

Classe 1
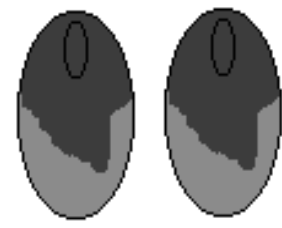

Classe 5
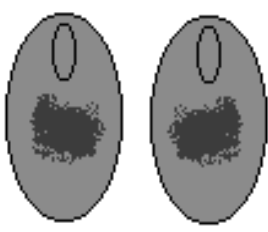

Classe 2
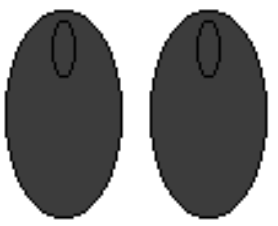

Classe 6

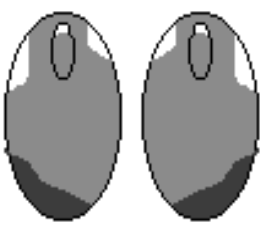

Classe 3

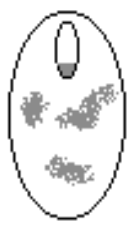

Classe 7

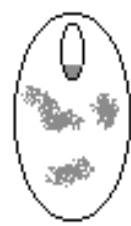

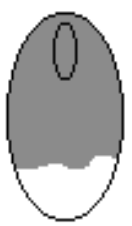

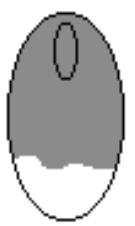

Classe 4

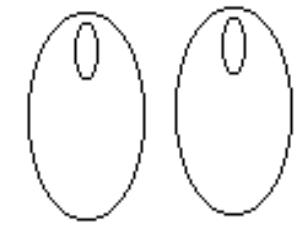

Classe 8

Legenda:

Vermelho intenso

Róseo

Branco leitoso

Figura 1. Representação diagramática das classes de semente encontradas no teste de tetrazólio para a espécie florestal Copaifera langsdorffii.

Figure 1. Representation of the class of seeds found in the tetrazolium test for the forest specie Copaifera langsdorffii.

Tabela 1. Porcentagens médias do teste de germinação e do teste de tetrazólio na avaliação da qualidade fisiológica de dois lotes de sementes de Copaifera langsdorffii.

Table 1. Average percentages of the germination test and the tetrazolium test in the evaluation of the physiological quality of two lots of seeds of Copaifera langsdorffii.

\begin{tabular}{lccc}
\hline Lotes & Amostras & Germinação & Tetrazólio \\
\hline 1 & 1 & $93 \mathrm{Aa}^{(1)}$ & $93 \mathrm{Aa}$ \\
& 2 & $92 \mathrm{Aa}$ & $93 \mathrm{Aa}$ \\
2 & 1 & $68 \mathrm{Ba}$ & $68 \mathrm{Ba}$ \\
& 2 & $68 \mathrm{Ba}$ & $73 \mathrm{Ba}$ \\
\hline
\end{tabular}

(1) Médias seguidas das mesmas letras maiúsculas na coluna e minúsculas na linha não diferem estatisticamente pelo Teste de Tukey a 5\% de probabilidade.

Schizolobium parahyba - guapuruvu

O pré-tratamento com escarificação seguida de embebição por 24 horas apresentou dificuldade na retirada do tegumento, apresentando assim muita variação na uniformidade de coloração. Muitas sementes não apresentaram coloração na região central do tecido de reserva e no eixo embrionário, colorindo-se apenas nas extremidades das sementes, devido aos danos causados pela retirada do tegumento, não permitindo a avaliação. Em soluções mais concentradas por períodos maiores de coloração, as sementes apresentaram coloração intensa e em alguns casos não houve coloração do cilindro central. $\mathrm{Na}$ adequação do teste de tetrazólio para sementes de rabanete, Delouche et al. (1976) escarificaram as sementes, permitindo a rápida embebição e facilitando a remoção do tegumento. Após, submeteram as sementes à embebição entre papel mata-borrão umedecido, durante uma noite. Em seguida ao pré-condicionamento, foi retirado o tegumento das sementes e elas foram colocadas em solução de tetrazólio a $1,0 \%$, por 1 a 2 horas, a $40{ }^{\circ} \mathrm{C}$. 
As sementes submetidas ao pré-tratamento de escarificação mecânica seguida de embebição por 48 horas, com retirada do tegumento, expostas a soluções de tetrazólio por 2 horas, independentemente da concentração, apresentaram coloração intensa na região escarificada, com manchas rosadas dispersas no tecido de reserva e no eixo embrionário. Considerando que o embrião, localizado na parte interna da semente, é a principal estrutura a ser analisada na determinação da viabilidade e vigor, a coloração da parte interna da semente é fundamental.

As condições de pré-tratamento, concentração da solução de tetrazólio e tempo de coloração são extremamente específicas de cada espécie. Utilizando sementes de Gleditschia amorphoides (sucará), Fogaça et al. (2006) obtiveram bons resultados com sementes escarificadas mecanicamente e embebidas por 48 horas, para posterior retirada do tegumento, e utilizando solução de tetrazólio de $0,075 \%$ por 3 horas, acondicionadas em câmara a $35^{\circ} \mathrm{C}$, no escuro. Com imbuia, Kalil-Filho et al. (2008) obtiveram bons resultados com embebição por 16 horas, com posterior retirada do tegumento e corte longitudinal através do centro do eixo embrionário, em solução de tetrazólio a $0,5 \%$ por 1 hora, em câmara a $40{ }^{\circ} \mathrm{C}$.

No presente trabalho, o melhor preparo foi o que utilizou sementes escarificadas mecanicamente, embebidas por 48 horas, com posterior retirada do tegumento, em solução de tetrazólio com concentração de $0,10 \%$ por 4 horas e $0,20 \%$ por 3 horas. As seguintes características foram consideradas ideais: tecido com coloração vermelha brilhante ou rósea, típica de tecido sadio, com todas as sementes coloridas de forma uniforme; identificação e diferenciação dos tecidos mortos que apresentaram coloração branca ou amarelada ou em deterioração com coloração vermelha intensa.

Para avaliação da eficiência do emprego do teste de tetrazólio, inicialmente caracterizaram-se os lotes 1 e 2, que apresentaram teor de água de 9,0 e 14,0\%, respectivamente. Para o desenvolvimento de coloração das sementes em solução de tetrazólio, optou-se por um dos melhores tratamentos da etapa anterior, ou seja, sementes escarificadas manualmente, embebidas por 48 horas, com posterior retirada do tegumento e expostas a solução de tetrazólio na concentração de $0,10 \%$, por 4 horas, a $35^{\circ} \mathrm{C}$, no escuro.

Com relação à comparação dos resultados do teste de tetrazólio com o teste de germinação dentro de cada lote avaliado, as amostras não apresentaram diferença significativa, demonstrando que a metodologia do teste de tetrazólio empregada estimou com eficiência a viabilidade das sementes analisadas (Tabela 2).

Tabela 2. Porcentagens médias do teste de germinação e do teste de tetrazólio na avaliação da qualidade fisiológica de dois lotes de sementes de Schizolobium parahyba.

Table 2. Average percentages of the germination test and the tetrazolium test in the evaluation of the physiological quality of two lots of Schizolobium parahyba seeds.

\begin{tabular}{lccc}
\hline Lotes & Amostras & Germinação $^{(1)}$ & Tetrazólio \\
\hline 1 & 1 & $75 \mathrm{Ba}$ & $77 \mathrm{Ba}$ \\
& 2 & $76 \mathrm{Ba}$ & $80 \mathrm{Ba}$ \\
2 & 1 & $80 \mathrm{Aa}$ & $85 \mathrm{Aa}$ \\
& 2 & $84 \mathrm{Aa}$ & $88 \mathrm{Aa}$ \\
\hline \multicolumn{1}{c}{ Médias seguidas da mesma letra, maiúscula na coluna e minúscula na linha não diferem entre }
\end{tabular}

si pelo teste Tukey a $5 \%$ de probabilidade.

Na figura 2 está representada em diagrama a classificação dos níveis de viabilidade encontrados na padronização do teste de tetrazólio para sementes de Schizolobium parahyba. As suas descrições são as seguintes:

Classe 1 Viável: semente com coloração rósea uniforme e todos os tecidos com aspecto normal e firme.

Classe 2 Viável: semente com coloração rósea uniforme e na região central dos cotilédones apresentando coloração vermelha intensa, sem atingir o eixo embrionário.

Classe 3 Viável: semente apresentando manchas brancas e leitosas, típica de tecido morto.

Classe 4 Inviável: mais de 50\% da região cotiledonar apresentando coloração vermelha intensa, tecidos em deterioração.

Classe 5 Inviável: região vascular e eixo embrionário com coloração branca e leitosa.

Classe 6 Inviável: semente totalmente com coloração vermelha intensa, indicando processo acentuado de deterioração.

Classe 7 Inviável: semente com eixo embrionário em processo de deterioração e seus cotilédones mortos.

Classe 8 Inviável: semente totalmente branca e leitosa, apresentando tecidos flácidos. 

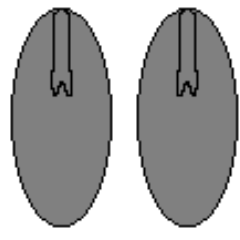

Classe 1
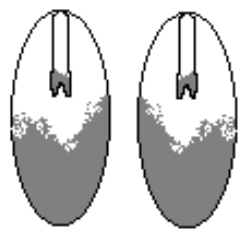

Classe 5
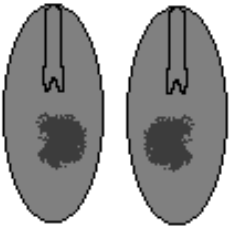

Classe 2

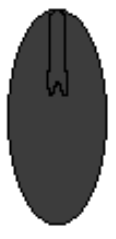

Classe 6

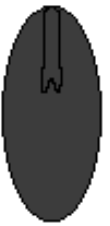

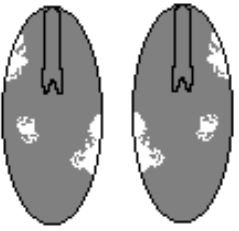

Classe 3

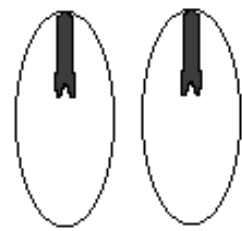

Classe 7

$\square$ Róseo

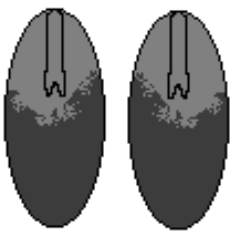

Classe 4

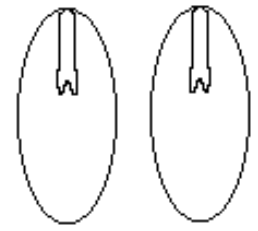

Classe 8

Legenda:

Vermelho intenso

Branco leitoso

Figura 2. Representação diagramática das classes de sementes encontradas no teste de tetrazólio para a espécie florestal Schizolobium parahyba.

Figure 2. Representation of the class of seeds found in the tetrazolium test for the forest specie Schizolobium parahyba.

Por se tratar de um teste rápido e confiável na análise de sementes, fornecendo mais rapidamente informações que o teste padrão de germinação, o teste de tetrazólio é recomendado para avaliação de várias espécies florestais, como: Aleurites fordii (tungue), Cedrela fisilis (cedro), Jacaranda micrantha (caroba), Leuhea divaricata (açoita-cavalo) e Hovenia dulcis (uva-do-japão) (AMARAL; ALCALAY, 1997); Kielmeyera coriacea (pau-de-santo) (DAVIDE et al., 1997); Magonia pubescens (tingui) (MALAVASI et al., 1997); Aspidosperma subincanum (peroba-de-gomo), Aspidosperma discolor (guatambu-vermelho) e Tabebuia alba (ipê-amarelo) (MATTEUCCI et al., 1999); Tapirira guianensis (guarucaia) (RAMOS et al., 1999); Albizia hasslerii (farinha-seca) (ZUCARELI et al., 2001); Astronium graveolens (guaritá), Jacaranda cuspidifolia (jacarandá) e Parapiptadenia rigida (angico) (FOGAÇA, 2003); Peltophorum dubium (canafístula) (OLIVEIRA et al., 2005); Gleditschia amorphoides (sucará) (FOGAÇA et al., 2006); Lafoensia pacari (mangaba-brava) (MENDONÇA et al., 2006) e Ocotea porosa (imbuia) (KALIL-FILHO et al., 2008).

Assim, pelos resultados obtidos neste trabalho, o teste de tetrazólio mostrou-se eficiente na determinação da viabilidade de sementes de copaíba e guapuruvu, quando comparados com o teste de germinação. Pela rapidez na obtenção dos resultados, o teste de tetrazólio é uma boa opção para o controle de qualidade de sementes das espécies estudadas.

\section{CONCLUSÕES}

As metodologias avaliadas que foram eficientes na obtenção de coloração satisfatória, permitindo a diferenciação dos tecidos, e na avaliação da qualidade fisiológica das sementes, quando comparadas com o teste padrão de germinação, foram:

- Copaíba - sementes escarificadas e embebidas por 24 horas, a $35^{\circ} \mathrm{C}$, com posterior retirada do tegumento, submetidas a solução de tetrazólio a $0,20 \%$ por 4 horas, a $35^{\circ} \mathrm{C}$, no escuro.

- Guapuruvu - sementes escarificadas e embebidas por 48 horas, a $35^{\circ} \mathrm{C}$, com posterior retirada do tegumento, submetidas a solução de tetrazólio a $0,10 \%$ por 4 horas, a $35^{\circ} \mathrm{C}$, no escuro.

Pela rapidez na obtenção dos resultados, o teste de tetrazólio é uma boa opção para o controle de qualidade de sementes das espécies estudadas, podendo ser empregado como um complemento ao teste de germinação. 


\section{REFERÊNCIAS}

AMARAL, D. M. I.; ALCALAY, N. Emprego do teste de tetrazólio em cinco espécies florestais do Rio Grande do Sul. In: CONGRESSO BRASILEIRO DE SEMENTES, 10., 1997, Foz do Iguaçu. Resumos... Curitiba: ABRATES, 1997. p. 221.

AMARAL, A. S.; PESKE, S. T. pH do exsudato para estimar, em 30 minutos, a viabilidade de sementes de soja. Revista Brasileira de Sementes, Brasília, v. 6, n. 3, p. 85 - 92, 1984.

BHÉRING, M. C.; SILVA, R. F.; ALVARENGA, E. M.; DIAS, D. N. F. S.; PENA, M. F. Avaliação da viabilidade e do vigor das sementes de feijão de vagem (Phaseolus vulgaris L.) pelo teste de tetrazólio. Viçosa, 1996. 27 p.

BRASIL. Ministério da Agricultura e Reforma Agrária. Regras para análise de sementes. Brasília: SNDA/ DNDV/ CLAV, 1992. 365 p.

COSTA, N. P.; MARCOS FILHO, J. O emprego do teste de tetrazólio na avaliação da qualidade de sementes de soja. Informativo ABRATES, Londrina, v. 4, n. 2, p. 53 - 63, 1994.

DAVIDE, A. C.; MALAVASI, M. M.; OLIVEIRA, L. M.; MACHADO, C. F.; TONETTI, O. A. O. Uso do teste de tetrazólio para avaliar a qualidade de sementes de pau-santo (Kielmeyera coriacea (Pr.) Mart.) - Guttiferae. In: CONGRESSO BRASILEIRO DE SEMENTES, 10., 1997, Foz do Iguaçu. Resumos... Curitiba: ABRATES, 1997. p. 219.

DELOUCHE, J. C.; STILL, T. W.; RASPET, M.; LIENHARD, M. O teste de tetrazólio para viabilidade da semente. Brasília: AGIPLAN, 1976. 103 p. 203). Appyed seed physiology. Mafes: Mississippi State University, 1995. 65 p. (Technology Bulletin,

FOGAÇA, C. A. Padronização e adequação de metodologias para avaliação da qualidade física e fisiológica de sementes de Gleditschia amorphoides Taub. - Caesalpinaceae. 95 p. Monografia (Conclusão do Curso de Agronomia) - UNIOESTE, Marechal C. Rondon, PR, 2000.

Padronização do teste de tetrazólio para avaliação da viabilidade de sementes de três espécies florestais. 53 f. Dissertação (Mestrado em Agronomia) - Faculdade de Ciências Agrárias e Veterinárias, Universidade Estadual Paulista, Jaboticabal, 2003.

FOGAÇA, C. A.; MALAVASI, M. M.; ZUCARELI, C.; MALAVASI, U. C. Aplicação do teste de tetrazólio em sementes de Gleditschia amorphoides Taub. Caesalpinaceae. Revista Brasileira de Sementes, Pelotas, v. 28, n. 3, p. 101 - 107, 2006.

FRANÇA NETO, J. B.; PEREIRA, L. A. G.; COSTA, N. P. Metodologia do teste de tetrazólio em sementes de soja. Londrina: EMBRAPA - CNP Soja, 1986. 35 p.

FRANÇA NETO, J. B. Teste de tetrazólio para determinação do vigor de sementes. In: KRYZANOWSKI, F. C.; VIEIRA, R. D.; FRANÇA NETO, J. B. Vigor de sementes: conceitos e testes. Londrina: ABRATES, 1999. 218 p.

FRANCO, D. F.; PETRINI, J. A.; AMARAL, A. S. Novo teste de viabilidade em sementes de soja. Pelotas: UEPAE, 1984. 3 p. (Relatório de Pesquisa, 10).

GRABE, D. F. Manual do teste de tetrazólio em sementes. Brasília: AGIPLAN, 1976. 85 p.

KALIL-FILHO, A. N.; LOPES, A. J.; RÊGO, G. M.; TOMACHITZ, A. Avaliação da qualidade fisiológica de sementes de imbuia pelo teste do tetrazólio. Pesquisa Florestal Brasileira, Colombo, n. 57, p. 69 - 72, 2008.

LORENZI, H. Árvores brasileiras: manual de identificação e cultivo de plantas arbóreas nativas do Brasil. v. 1.3 ed. Nova Odessa: Editora Plantarum, 384 p. 2000.

MALAVASI, M. M.; DAVIDE, A. C.; OLIVEIRA, L. M.; MACHADO, C. F.; TONETTI, O. A. O. 
Avaliação da qualidade fisiológica de sementes de tingui (Magonia pubescens St.-Hil. - Sapindaceae) através do teste de tetrazólio. In: CONGRESSO BRASILEIRO DE SEMENTES, 10., 1997, Foz do Iguaçu. Resumos... Curitiba: ABRATES, 1997. p. 217.

MATTEUCCI, M. B. A.; GUIMARÃES, N. N. R.; TIVERON FILHO, D. Utilização do teste de tetrazólio na verificação da viabilidade de germinação de três espécies do cerrado: peroba-de-domo (Aspidosperma subincanum Mart.), guatambu-vermelho (Aspidosperma discolor A. DC.) e ipê-amarelo (Tabebuia alba (Cham.) Sandw.), armazenadas em câmara fria por 3, 4 e 5 anos. Informativo ABRATES, Curitiba, v. 9, n. 1/2, p. 186, 1999.

MENDONÇA, E. A. F.; COELhO, M. F. B.; LUCHESE, M. Teste de tetrazólio em sementes de mangaba-brava (Lafoensia pacari St.-Hil. - Lythraceae). Revista Brasileira de Plantas Medicinais, Botucatu, v. 8, n. 2, p. 33 - 38, 2006.

MORENO, E. M. Analises físico y biológico de semillas agricolas. México: Universidad Nacional Autônoma de México, 1984. 383 p.

NASCIMENTO, W. M. O.; CARVALHO, N. M. Determinação da viabilidade de sementes de jenipapo (Genipa americana L.) através do teste de tetrazólio. Revista Brasileira de Sementes, Brasília, v. 20, n. 2, p. 470 - 474, 1998.

OLIVEIRA, L. M.; CARVALHO, M. L. M.; DAVIDE, A. C. Teste de tetrazólio para avaliação da qualidade de sementes de Peltophorum dubium (Sprengel) Taubert Leguminosae Caesalpinioideae. Cerne, Lavras, v. 11, n. 2, p. 159 - 166, 2005.

PIÑA-RODRIGUES, F. C. M.; SANTOS, N. R. F. Teste de tetrazólio. In: PIÑA-RODRIGUES, F. C. M. (Coord.). Manual de análise de sementes florestais. Campinas: Fundação Cargill, 1988. p. 91 - 100.

RAMOS, K. M. O.; BUENO, P. C.; SALOMÃO, A. N. Determinação da temperatura de germinação e do comportamento para fins de conservação de sementes de Tapirira guianensis Aubl. - Anacardiaceae. Informativo ABRATES, Curitiba, v. 9, n. 1/2, p. 73, 1999.

ZUCARELI, C.; MALAVASI, M. M.; FOGAÇA, C. A.; MALAVASI, U. C. Preparo e coloração de sementes de farinha-seca (Albizia hasslerii (Chodat) Bur.) para o teste de tetrazólio. Revista Brasileira de Sementes, Brasília, v. 23, n. 2, p. 186 - 191, 2001. 
